\title{
Australian Journal of Crop Science \\ Effect of high night temperatures during anthesis on cotton (Gossypium hirsutum L.) pistil and leaf physiology and biochemistry
}

\author{
Dimitra A. Loka*, Derrick M. Oosterhuis
}

\begin{abstract}
Altheimer Laboratory, Department of Crop, Soil and Environmental Sciences, University of Arkansas, Fayetteville, AR 72704, USA
\end{abstract}

\section{*Corresponding author: dimloka@gmail.com}

\begin{abstract}
Flowering in cotton is a sensitive stage to heat stress but the effects of high night temperatures on cotton's pistil metabolism are not well understood. The objective of this study was to evaluate the effects of high night temperatures on the carbohydrate, glutathione reductase and free polyamine content of the cotton pistil and its subtending leaf. Growth chamber experiments were conducted using cotton (Gossypium hirsutum L.) cultivar ST5288B2F. Treatments consisted of normal day/night $\left(32 / 24^{\circ} \mathrm{C}\right)$ and high night temperatures $\left(32 / 30^{\circ} \mathrm{C}\right)$ for two weeks at flowering. Pistil glucose and sucrose concentrations were significantly increased under conditions of high night temperatures and the same pattern was observed for starch concentrations. However, even though leaf respiration increased, only heat-stressed leaf starch levels were significantly lower compared to the control. In contrast, leaf glutathione reductase was significantly increased under high night temperatures while pistil glutathione reductase remained similar under both control and stress conditions. High night temperatures significantly increased leaf and pistil putrescine content, but had no effect on leaf and pistil spermidine content. Spermine content was significantly increased in the pistil but not in the leaf. In conclusion, leaf antioxidant metabolism appeared to be more efficient in protecting leaf carbohydrate metabolism under high night temperatures since reductions were observed only in leaf starch levels. Contrary to that, pistil antioxidant mechanism appeared less sensitive to the high night temperature stress and despite increases in pistil polyamine content accumulation of glucose, sucrose and starch concentrations was observed indicating a perturbation in carbohydrate metabolism.
\end{abstract}

Keywords: antioxidants, cotton, carbohydrates, gas exchange, polyamines, reproductive units.

Abbreviations: GR_glutathione reductase, PAs_polyamines, PUT_putrescine, SPD_spermidine, SPM_spermine

\section{Introduction}

Temperature is a major factor affecting plant growth with higher than optimum temperatures disrupting physiological and metabolic procedures and contributing to yield variability (Singh et al., 2007; Hedhly et al., 2009). Cotton is a perennial with a complicated and indeterminate growth habit that originates from hot and arid areas but the optimum temperature range for its metabolic and biochemical activities is estimated to be between 25 and $31^{\circ} \mathrm{C}$ (Burke and Wanjura, 2010). As a consequence, the higher than optimum day temperatures $\left(>32^{\circ} \mathrm{C}\right)$ that normally occur in cotton growing areas around the world have been reported to significantly compromise cotton reproductive efficiency due to inhibition of photosynthesis (Snider et al., 2011), reduced pollination and fertilization (Oosterhuis and Snider, 2011), decreased flower setting and lower growth rates (Reddy et al., 1996). Recent climate projections though have indicated that night temperatures are expected to rise faster and to a greater extent compared to day temperatures (IPCC, 2007). Although plants are susceptible to heat stress at almost all growth and developmental stages, the reproductive stage appears to be more vulnerable than vegetative (Couee et al., 2006) and research in several crops, such as rice (Oryza sativa) (Mohammed and Tarpley, 2009; 2010), cowpea (Vigna unguiculata L.) (Warrag and Hall, 1984; Ahmed and Hall, 1993), wheat Triticum aestivum) (Prasad et al., 2008), sorghum (Sorghum bicolor L.) (Prasad and Djanaguiraman,
2011), and soybean (Glycine max L.) (Djanaguiraman et al., 2013) has indicated that high night temperatures during the reproductive phase have a detrimental effect on yield. These reductions have been attributed to increased male sterility and floral abscission (Warrag and Hall, 1984; Guinn, 1974), floral bud suppression and decreased pollen viability (Mohammed and Tarpley, 2009; Singh et al., 2007) as well as lower seed-set rate (Peet and Bartholemew, 1996; Prasad et al., 2008; Mohammed and Tarpley, 2009); however, the physiological and metabolic explanations are missing. In cotton, yield reductions due to decreased boll setting (Yoon et al., 2009), increased fruit shedding rates (Arevalo et al., 2008) and decreased number of seeds per boll (Echer et al., 2014) have also been observed when increased night temperatures occurred during cotton's reproductive period but little to zero attention has been given to the effects of increased night temperatures on the physiology and metabolism on cotton's reproductive units.

Loka and Oosterhuis (2010) reported that high night temperatures increased leaf respiration and resulted in decreases in adenosine triphosphate levels and carbohydrate content but their research focused on the vegetative stage of cotton growth with no information existing on reproductive stage. Carbohydrate metabolism is closely associated with plant growth since the photosynthate assimilate exported from the photosynthesizing tissues provides the carbon 
skeletons for the growth and maintenance of nonphotosynthesizing tissues. Snider et al. (2011) reported that high day temperatures during cotton's flowering stage affected carbohydrate availability to sink tissues but the effect of elevated night temperatures on carbohydrate balance was not investigated.

Apart from their effect on carbohydrate metabolism, increased respiration rates have also been observed to lead in increased production of reactive oxygen species (McDonald and Vanleberghe, 2005) that can have significant toxic effects on plant metabolism depending on the antioxidant status of the plant. Glutathione reductase (GR), a component of the plant antioxidative system of the plants (Liu et al., 2013), has been reported to play a critical role in embryo and meristem development (Reicheld et al., 2007; Frottin et al., 2009 ) with its concentrations controlling male sterility in the anthers (Selote and Khanna-Chopra, 2004; Fu et al., 2010). Additionally, polyamines (PAs), a group of secondary metabolites that controls flowering and reproductive development, have also been shown to be active under adverse environmental conditions (Oosterhuis and Loka, 2012 and references therein), with their concentrations affecting not only GR activity (Verma and Mishra, 2005; Liu et al., 2007) but also carbohydrate metabolism (Kaplan et al., 2004).

Considering that the major source of photosynthate for a cotton boll is its subtending leaf, with more than $60 \%$ of carbohydrates imported from it (Ashley, 1972) the aim of this study was to monitor the effects of high night temperatures on the physiology and metabolism of the cotton pistil and subtending leaf. Hence, the objectives of our study were to evaluate the effect of high night temperatures on the carbohydrate, GR and PAs content of the cotton pistil and subtending leaf. The tested hypothesis was that high night temperatures would increase leaf respiration rates, resulting in significant increases in GR and PAs content in both the pistil and the leaf which would prevent changes in the carbohydrate balance of the pistil and its subtending leaf.

\section{Results}

\section{Leaf photosynthesis and respiration levels}

Photosynthesis rates of the subtending to the flower leaf remained unaffected of the high night temperatures treatments the first and the second week of the study (Fig. 1A). No significant interaction was observed between the main factors $(\mathrm{P}=0.58$ for photosynthesis and $\mathrm{P}=0.73$ for respiration) and the effect of temperature was analyzed using Student't $t$-test for each week. An insignificant raise of $2.8 \%$ and $2.1 \%$ was noticed the first and second week, respectively, for the photosynthetic rates of the plants grown under high night temperatures compared to the control. Contrary to that, leaf respiration rates of the heat-stressed plants were significantly increased compared to the control by $21 \%$ at the end of the second week of the study (Fig 1B).

\section{Leaf and pistil glutathione reductase (GR) levels}

Levels of pistil GR remained unaffected by the high night temperatures during both weeks of the experiment (Fig.2B). The effects of heat stress were analyzed for each week using a Student's $t$-test since no significant interaction was observed between the main factors, temperature and time $\left(\mathrm{P}_{\text {LEAF GR }}=0.48, \mathrm{P}_{\text {PISTIL GR }}=0.87\right)$. Elevated night temperatures had no significant effect on GR content of the pistils other than a $7 \%$ decrease the first week and a $2.5 \%$ decrease the second week compared to the control. Nevertheless, leaf GR concentrations of the heat-stressed plants were significantly affected (Fig.2A). Subtending leaves of plants grown under $32 / 30^{\circ} \mathrm{C}$ had significantly higher GR levels the first (80\%) and the second (57\%) week after stress initiation.

\section{Leaf and pistil polyamine concentrations}

Both pistil and leaf polyamine levels were affected by high night temperatures compared to the control. A significant increase in pistil PUT and SPM concentration of plants grown at $32 / 30^{\circ} \mathrm{C}$ was observed compared to those grown at $32 / 24^{\circ} \mathrm{C}$ (Fig. 3B). Pistil PUT content was increased by $24 \%$ under high night temperatures compared to the control while heat-stressed pistils contained $45 \%$ more SPM compared to those of control. The opposite pattern was observed in pistil spermidine levels where SPD content of pistils grown under elevated night temperatures was decreased however, nonsignificantly by $14 \%$ compared to the control.

A marked increase was observed in the leaf PUT levels of the subtending leaves with heat-stressed leaves containing 3.5-fold PUT compared to the leaves grown under control temperatures (Fig. 3A). Leaf SPD and SPM content was also increased, $17 \%$ for SPD and $7 \%$ for SPM, under conditions of high night temperatures, but non-significantly compared to the control.

\section{Leaf and pistil non-structural carbohydrate content}

High night temperatures significantly affected pistil glucose, sucrose and starch content the second week after the initiation of the temperature treatment. Pistil fructose concentrations remained unaffected (data not shown). No significant interaction was observed between the main factors (temperature and time, $\mathrm{P}_{\mathrm{LEAF}} \mathrm{GLU}=0.21, \mathrm{P}_{\mathrm{PISTIL}} \mathrm{GLU}=0.28$, $\mathrm{P}_{\text {LEAF SUC }}=0.34, \mathrm{P}_{\text {PISTIL SUC }}=0.13, \mathrm{P}_{\text {LeAF STARCH }}=0.99, \mathrm{P}_{\text {PISTIL }}$ STARCH $=0.11)$ and the effect of temperature on carbohydrate levels was analyzed using Student's $t$-test. No significant effect of high night temperatures was observed on glucose levels for the first week with the heat-stressed pistils having their glucose levels increased only by $9 \%$ compared to those of the control of the control temperature (Fig. 4B). However, at the end of the second week pistils grown at $32 / 30^{\circ} \mathrm{C}$ had $41 \%$ significantly more glucose than those grown at $32 / 24^{\circ} \mathrm{C}$. A similar pattern was observed in pistil sucrose concentrations, with high night temperatures leaving unaltered sucrose concentrations, only $9 \%$ increase compared to the control by the end of the first week, while sucrose content of heat-stressed pistils significantly increased by $33 \%$ the second week compared to the non-stressed pistils (Fig. 4D). Starch concentrations of pistils grown under high night temperatures were similar to those of the control during the first week after the stress was imposed with a non-significant increase. High night temperatures however, resulted in a significant increase $(83 \%)$ in pistil starch concentrations the second week after stress imposition compared to normal temperatures (Fig. 4F).

Leaf carbohydrate metabolism was also affected by increased high night temperatures. Unlike pistil carbohydrate concentrations, elevated night temperatures had no significant effect on leaf glucose levels the first and the second week after imposition of stress compared to the control (Fig. 4A). Similarly, a non-significant decrease by 1.6 and $2 \%$ respectively, was observed the first and the second week in the leaf sucrose levels of plants grown at $32 / 30^{\circ} \mathrm{C}$ compared to those grown at $32 / 24^{\circ} \mathrm{C}$ (Fig. 4C). Leaf starch 

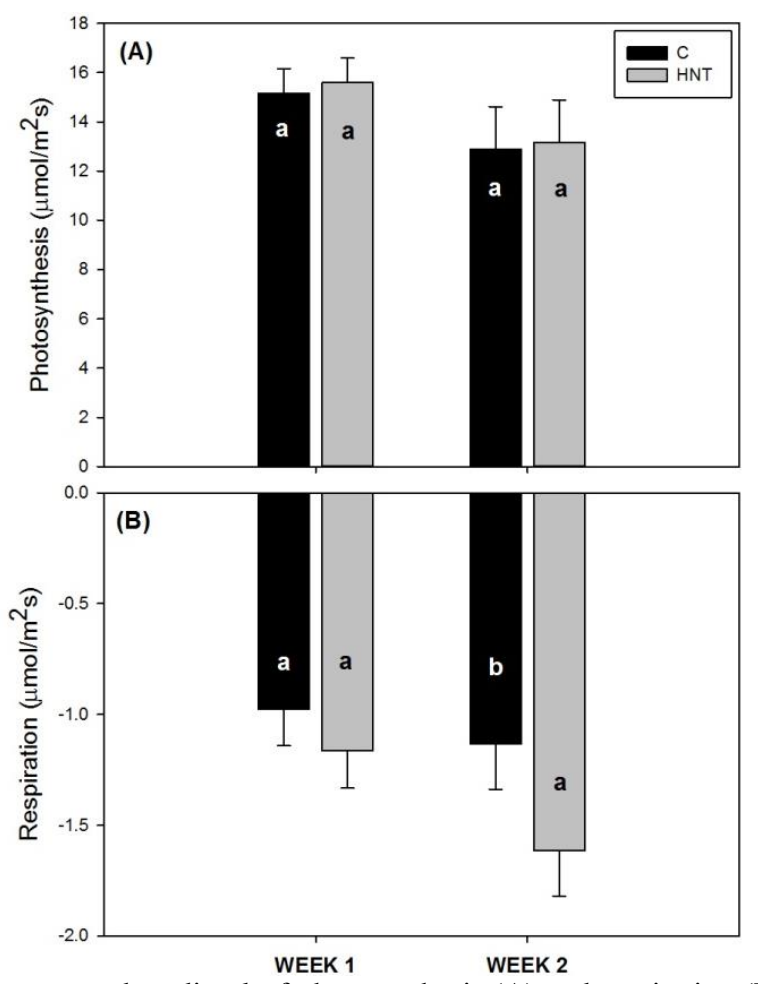

Fig 1. Effect of high night temperatures on subtending leaf photosynthesis (A) and respiration (B) at the end of the first and second week after initiation of the treatment. Columns connected with different letters are significantly different $(\mathrm{P}=0.05)$. Error bars represent \pm 1 standard error. (C: control temperatures $32 / 24^{\circ} \mathrm{C}$, HNT: high night temperatures $32 / 30^{\circ} \mathrm{C}$ ).
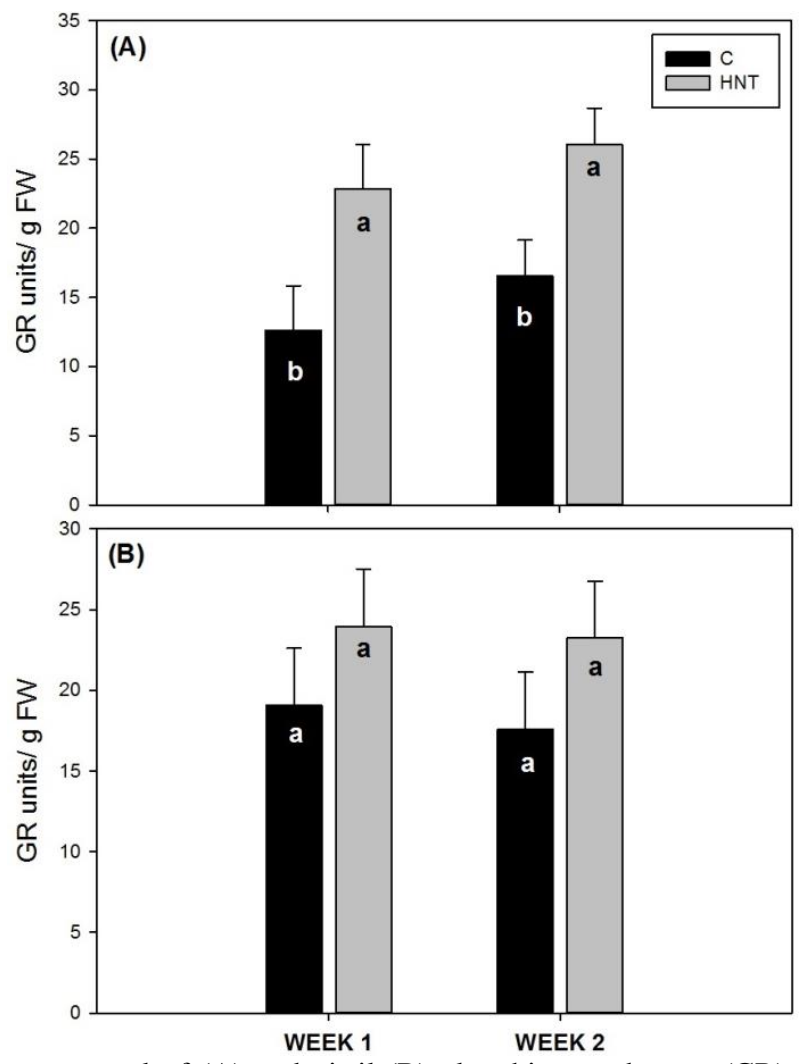

Fig 2. Effect of high night temperatures on leaf (A) and pistil (B) glutathione reductase (GR) content at the end of the first and second week after initiation of the treatment. Columns connected with different letters are significantly different $(\mathrm{P}=0.05)$. Error bars represent \pm 1 standard error. (C: control temperatures $32 / 24^{\circ} \mathrm{C}$, HNT: high night temperatures $32 / 30^{\circ} \mathrm{C}$ ). 
concentrations however, were significantly decreased under conditions of high night temperature stress the second week after imposition of stress by $19 \%$ compared to the control while no significant difference was observed the first week between leaf starch content of heat-stressed plants and those of control (Fig. 4E).

\section{Discussion}

Photosynthesis and respiration, the basic metabolic processes that control plant growth and development, are largely dependent on abiotic factors and especially on temperature. Photosynthesis, in particular, is considered as one of the most heat-sensitive processes in plants, with its rates significantly decreasing under conditions of heat stress. Nevertheless, variable responses have been reported on the effect of high night temperatures on photosynthesis. Prasad and Djanaguiraman (2011) and Djanaguiraman et al. (2013) reported lower leaf photosynthetic rates for sorghum and soybean plants, respectively, grown under high night temperatures. The opposite was observed by Kanno et al. (2009) and Turnbull et al. (2002) while Mohammed and Tarpley (2009) indicated that increased night temperatures had no effect on photosynthesis in rice. In accordance to Mohammed and Tarpley (2009) rates of the subtending to a flower leaf remained unaffected by high night temperatures in our study, leading us to speculate that heat stress during the night has not a significant effect on photosynthesis contrary to heat stress occurring during the day (Snider et al., 2009).

In contrast with photosynthesis, leaf respiration rates of heat-stressed plants in our study were significantly higher compared to the control. Increases in leaf respiration rates under conditions of high night temperatures during flowering have been reported in a variety of other crops (Mohammed and Tarpley, 2009; Prasad and Djanaguiraman, 2011; Djanaguiraman et al., 2013). Additionally, Loka and Oosterhuis (2010) reported higher respiration rates for plants grown under high night temperatures during cotton's vegetative stage, leading us to conclude that cotton leaf respiration is equally responsive to night temperature changes during both its vegetative and reproductive stage.

Increases in production of reactive oxygen species (ROS) due to imbalances between photosynthesis and respiration rates and consequently oxidative damage is a common occurrence under conditions of heat stress (Fitter and Hay, 1987) with the extent of the damage being dependent on the efficiency of the plant's antioxidative mechanism. As the results indicated, leaf antioxidant metabolism was promptly activated by high night temperatures, increasing GR concentrations by $80 \%$ and $46 \%$ the first and the second week, respectively. Previous research has indicated that GR levels increase under conditions of heat stress (Dat et al., 1998; Dash and Mohanty, 2002) and similar to our results, Mohammed and Tarpley (2009) reported that high night temperatures significantly increased total antioxidant capacity of rice leaves. In spite of the significant changes in GR leaf concentrations, pistil GR levels remained essentially unaltered under high night temperatures. Contrary to our results, Snider et al. (2009) reported higher levels of GR in heat-stressed pistils compared to the control, but their heat stress treatment was during the day. Taking into consideration that heat stress has differential responses on plant physiology depending on the light exposure (Schrader et al., 2004) it is concluded that pistil GR metabolism is relatively unresponsive to heat stress occurring during the night.
Insufficiencies in the antioxidative mechanism of plants, however, have been reported to be compensated by upregulations in other components of the mechanism (Willekens et al. 1997) and this appears to be the case in our experiment since pistil PUT and SPM concentrations were significantly increased under elevated night temperatures compared to the control. Previous research has indicated that an increase in PAs levels is the plants common response to higher than optimum temperatures and other abiotic stresses (Kumar et al. 2006; Bitrian et al. 2012) since stress tolerance is closely connected with maintenance of high concentrations of PAs (Liu et al., 2007, Bitrian et al., 2012). In contrast to our results, Bibi et al. (2010) in experiments on cotton reported that PUT levels of heat-stressed cotton ovaries remained similar to the control while SPD and SPM levels decreased, but their experiments dealt with heat stress during the day. Similarly to our results, Alcazar et al. (2011) reported increases in both PUT and SPM in Craterostigma plantagineum plants under water-deficit stress, while Song et al. (2002) reported over-accumulation of PUT in anthers of tomato (Lycopersicon esculentum L.) under conditions of heat stress. Considering that PUT, apart from acting as a powerful antioxidant (Drolet et al., 1986; Kim et al., 2002), has been reported to affect and control the activities of several antioxidant enzymes, including GR (Verma and Mishra, 2005; Liu et al., 2007) we assume that the lack of response from GR under high night temperatures stress resulted in over-production of PUT which consequently increased SPM concentrations to maintain homeostasis in plant cells.

In support of our assumption, leaf SPD and SPM levels were unaffected from elevated night temperatures with only PUT content increasing almost 3-fold. Similar results to ours were reported under cold temperatures treatment (Kim et al., 2002; Cuevas et al., 2009) as well as under water-deficit stress (Alcazar et al., 2010; Loka et al., 2013) and salt stress (Roy and Wu, 2001; Quinet et al., 2010). Despite SPD and SPM being more associated with plant response to heat stress, SPD and SPM concentrations in our experiment did not alter. We speculate that this was due either to the sufficient protection provided from GR or to the canalization of PUT straight into SPM without increases in its content as indicated by Alcazar et al. (2010).

Temperature, as any exogenous factor, which alters the availability of substrate from source and its utilization within the sink is expected to disturb plant metabolism and influence partitioning of carbohydrates. Decreases in carbohydrate content have been reported to be the common response of plants to heat stress (Snider et al., 2009; Loka and Oosterhuis, 2010) due to significant increases in respiration rates (Salvucci and Crafts-Brandner, 2004) and concomitant decreases in leaf photosynthetic rates (Reddy et al., 1997). Nevertheless, that was not the case in our experiments, where even though respiration rates significantly increased, while photosynthesis remained unaffected under elevated night temperatures, leaf carbohydrates remained similar to the control with the exception of starch which decreased. Contrary to our results, Loka and Oosterhuis (2010) reported significant decreases in leaf hexose and sucrose concentrations; however, sampling time in their experiment was at the end of the dark period and not in the middle of light period. Additionally, the stress in their experiments was imposed not only during a different growth stage but also at a different severity and duration. In partial accordance with our results are those of Echer et al. (2014) who in experiments on cotton observed that night-time heat stress had no effect on leaf carbohydrates when it was applied during the floral bud 


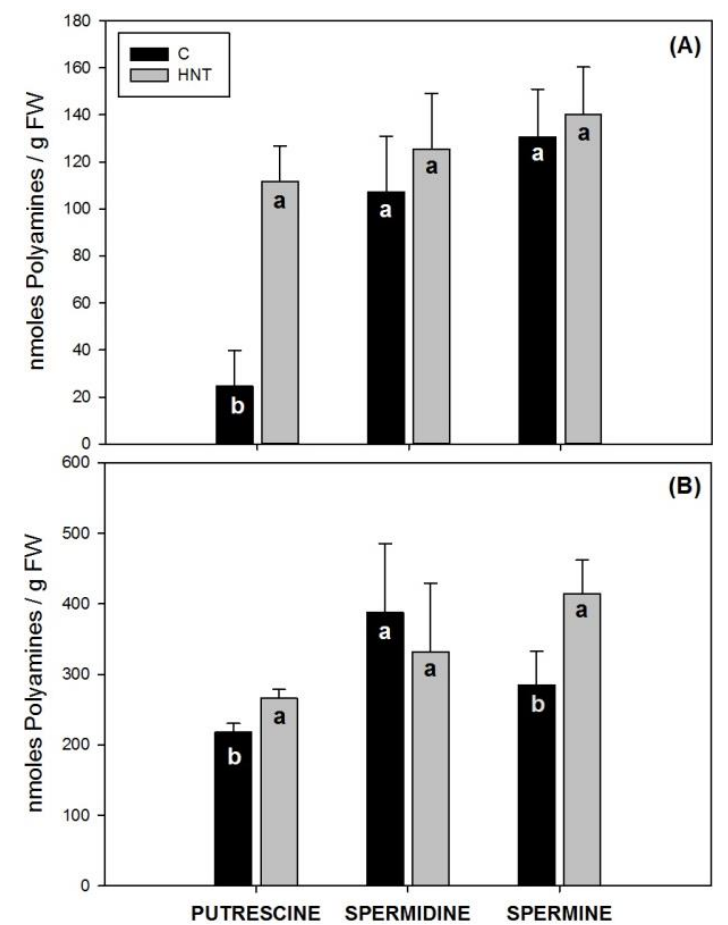

Fig 3. Effect of high night temperatures on leaf (A) and pistil (B) polyamine (putrescine, spermidine, spermine) content at the end of the second week after initiation of the treatment. Columns connected with different letters are significantly different $(\mathrm{P}=0.05)$. Error bars represent \pm 1 standard error. (Control: control temperatures $32 / 24^{\circ} \mathrm{C}$, HNT: high night temperatures $32 / 30^{\circ} \mathrm{C}$ ).
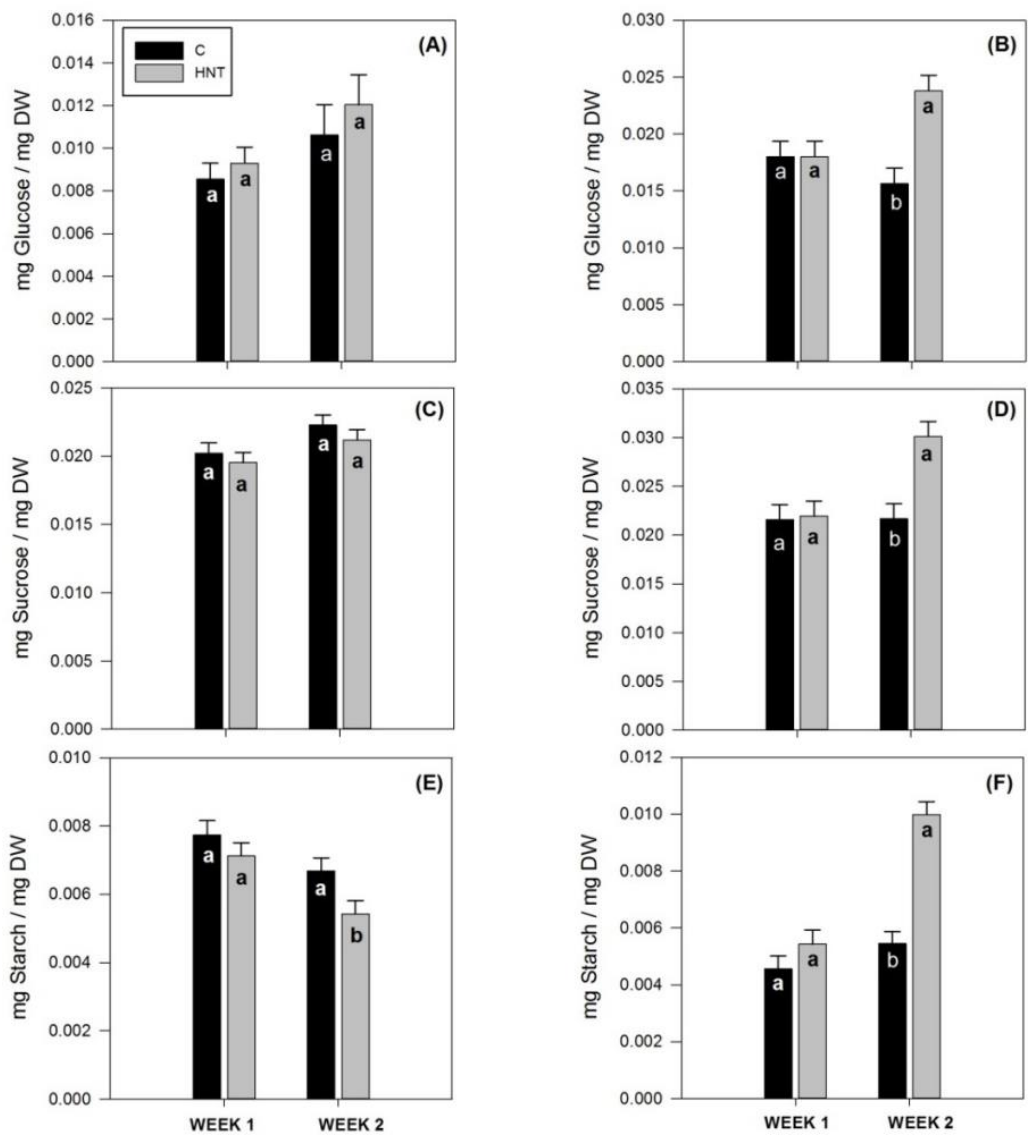

Fig 4. Effect of high night temperatures on leaf (A) and pistil (B) glucose content, leaf (C) and pistil (D) sucrose content, leaf (E) and pistil (F) starch content at the end of the first and second week after initiation of the treatment. Columns connected with different letters are significantly different $(\mathrm{P}=0.05)$. Error bars represent \pm 1 standard error. (C: control temperatures $32 / 24^{\circ} \mathrm{C}$, HNT: high night temperatures $32 / 30^{\circ} \mathrm{C}$ ). 
stage, whereas a decrease in leaf glucose was observed at the flowering stage. Previous research on the effects of high night temperatures on carbohydrate balance is rather limited. Lawrence and Holaday (2000) indicated that hexose and sucrose content of expanding cotton leaves grown at temperatures of $30 / 28^{\circ} \mathrm{C}$ (day/night) were similar to those grown at $30 / 19^{\circ} \mathrm{C}$ in contrast to Dinar and Rudich (1985) who reported increases in sucrose and concomitant decreases in starch levels of tomato leaves. We speculate that the decreases in starch content observed in our experiment were to alleviate the increased respiration rates caused by high night temperatures whereas the lack of any difference in glucose and sucrose concentrations were due to the efficiency of the antioxidative mechanism of the plant that protected photosynthesis and then carbohydrate production rates.

In contrast to leaf carbohydrate metabolism, pistil carbohydrate metabolism was significantly affected by high night temperatures with heat-stressed pistils containing higher glucose, sucrose and starch concentrations than the control. Snider et al. (2009) in experiments with heat stress during the day reported decreases in sucrose concentrations of heat-stressed cotton pistils but we speculate that the differential responses were due to heat stress occurring during the night and not during the day (Warrag and Hall, 1987; Peet and Bartholomew, 1996). Increases in cotton pistil sucrose content were also observed by Echer et al. (2014) when high night temperatures were imposed during cotton's floral bud stage. Similar accumulations of sucrose and starch in reproductive units under conditions of elevated night temperatures have also been reported by Dinar and Rudich (1985) and they were attributed to disruptions in sucrose and starch degradation. Nevertheless, Couee et al. (2006) suggested that accumulations of soluble sugars under conditions of stress was part of the plant's defensive mechanism against oxidative stress, which seems to be the case in our study, since GR levels of heat-stressed pistils were similar to the control.

\section{Materials and Methods}

\section{Growing conditions and plant material}

Growth chamber studies were conducted and repeated at the Altheimer Laboratory, University of Arkansas. Cotton (Gossypium hirsutum L.,) cultivar ST5288B2F (Bayer CropScience, Research Triangle Park, NC) was planted in 2L pots containing horticulture mix \#2 (SunGro Distribution Inc., Bellevue, WA). Pots were arranged in a growth chamber (Conviron PGW36) that was equipped with incandescent and fluorescent lamps and set for a $14 \mathrm{~h}$ photoperiod with a photosynthetic flux density (PPFD) of $800-850 \mu \mathrm{mol} / \mathrm{m}^{2} \mathrm{~s}$ and a relative humidity of $60 \%$. Half-strength Hoagland's nutrient solution was applied daily to all pots in order to maintain adequate nutrients and water. Plants were grown until the first flower stage (approximately eight weeks after planting) under normal day/night temperatures of $32 / 24^{\circ} \mathrm{C}$ (maximum during the day, minimum during the night, respectively) simulating a normal diurnal variation.

\section{Treatments}

At the first flower stage pots were divided in two groups and one group was transferred into a second growth chamber, with similar conditions of photon flux density, humidity and photoperiod as the first chamber, but with night temperatures raised to $30^{\circ} \mathrm{C}$ for $6 \mathrm{~h}$ at the start of the dark period (1800$2400 \mathrm{~h}$ ) and a gradual decrease to $24^{\circ} \mathrm{C}$, for an overall duration of two weeks, while the control plants remained under normal conditions $\left(32 / 24^{\circ} \mathrm{C}\right)$.

\section{Traits measured}

Measurements of photosynthesis, respiration, carbohydrate concentrations, glutathione reductase levels and free polyamines content were conducted at the end of the first and second week from a total of 80 plants (20 replications for each week-group) in each study.

\section{Experimental design and statistical analysis}

The experimental design was a two-factor factorial, the two factors being temperature and time (weeks), with 40 replications in each of the temperature treatment. To account for any differences between the growth chambers and to ensure the consistency of the results, the growth chamber used for the high night temperature treatment $\left(32 / 30^{\circ} \mathrm{C}\right.$, day/night) in the first study, was used for the control treatment $\left(30 / 24^{\circ} \mathrm{C}\right.$, day/night) in the second study. No significant effect on any of the parameters measured was found between the two studies $(\mathrm{P}>0.05)$ and the data was combined from the two consecutive studies for statistical analysis. No significant interaction was observed between the two factors across all measurements and the effects of temperature were analyzed for each week using a Student's ttest (JMP 11 software, SAS Institute Inc., Cary, NC, USA). Means were considered significantly different at $\mathrm{P} \leq 0.05$.

\section{Photosynthesis and respiration measurements}

A Li-Cor Model 6200 portable photosynthesis system (LiCor Inc. Lincoln, NE) was used to determine photosynthetic and respiratory rates for the attached subtending to the first position flower leaf from the $7^{\text {th }}$ (first week) and $9^{\text {th }}$ (second week) node of each plant. Measurements of photosynthesis and respiration were taken at $1200 \mathrm{~h}$ and $2300 \mathrm{~h}$, respectively, and the results were expressed as $\mu \mathrm{mol} / \mathrm{m}^{2} \mathrm{~s}$. Measurements of respiration were taken $3 \mathrm{~h}$ into the dark period in order to avoid the respiratory burst that follows the end of the light period.

\section{Glutathione reductase measurements}

Glutathione reductase was extracted and measured from first position cotton flowers and their subtending leaves from the $7^{\text {th }}$ (first week) and $9^{\text {th }}$ (second week) node of each plant $(\mathrm{n}=9)$ sampled at $1200 \mathrm{~h}$ according to the methods described by Loka and Oosterhuis (2014). Glutathione reductase activity was expressed as GR units /gr FW (fresh weight).

\section{Polyamine measurements}

Concentrations of diamine putrescine (PUT), triamine spermidine (SPD) and tetramine spermine (SPM) of first position cotton flowers from the $9^{\text {th }}$ node of each plant $(n=8)$ and their subtending leaves $(n=8)$ were sampled at $1200 \mathrm{~h}$ at the end of the second week and measured according to Loka et al. (2013). The results were expressed as nmoles polyamine /gr FW (fresh weight).

\section{Carbohydrate measurements}

First fruiting position cotton flowers from the $7^{\text {th }}$ (first week) and $9^{\text {th }}$ (second week) node of each plant $(n=10)$ and their subtending leaves $(n=10)$ were sampled at $1200 \mathrm{~h}$. Glucose 
and sucrose content of the pistils and their subtending leaves was measured according to the method described by Loka and Oosterhuis (2014). Starch was analyzed and determined according to Hendrix (1990). The results were expressed as $\mathrm{mg} / \mathrm{mg}$ DW (dry weight).

\section{Conclusions}

In conclusion, high night temperatures caused a significant increase in leaf respiration rates. Contrary to our hypothesis, this did not result in decreases in leaf photosynthetic rates or leaf carbohydrate content due to the efficient co-operation of leaf antioxidant and PA metabolism. In contrast, pistil antioxidant metabolism was largely unresponsive to the elevated night temperature stress and despite the significant increases in pistil PUT and SPM levels, pistil carbohydrate metabolism was significantly affected resulting in significant carbohydrate accumulations. Since previous research has indicated that decreases (Snider et al., 2009) or increases (Echer et al., 2014) in the carbohydrate content of the cotton pistil result in yield decreases we speculate that the significant increases in pistil glucose, sucrose and starch contents observed in the present study could have a significant effect on yield. With the prospect of night temperatures increasing faster and to a greater extent that day temperatures in the future, it is apparent that further research is needed in order to elucidate the effect of high night temperatures on carbohydrate partitioning into fruit and yield under controlled and field conditions.

\section{References}

Ahmed FE, Hall AE (1993) Heat injury during early floral bud development in cowpea. Crop Sci. 33:764-767.

Alcazar R, Planas J, Saxena T, Zarza X, Bortolotti C, Cuevas H, Bitrian M, Tiburcio AF, Altabella T, (2010) Putrescine accumulation confers drought tolerance in transgenic Arabidopsis plants over-expressing the homologous Arginine decarboxylase 2 gene. Plant Phys Biochem. 48:547-552

Alcazar R, Bitrian M, Bartels D, Koncz C, Altabella T, Tiburcio A (2011) Polyamine metabolic canalization in response to drought stress in Arabidopsis and the resurrection plant Cratersostigma plantagineum. Plant Signal Behav. 6:243-250.

Arevalo LM, Oosterhuis DM, Coker DL, Brown RS (2008) Physiological response of cotton to high night temperatures. Am J Plant Sci Biotech. 2:63-68.

Ashley DA (1972) C-labelled photosynthate translocation and utilization in cotton plants. Crop Sci. 12:60.

Bibi AC, Oosterhuis DM, Gonias ED (2010) Exogenous application of putrescine ameliorates the effect of high temperature in Gossypium hirsutum L. flowers and fruit development. J Agron Crop Sci. 196:205-211.

Bitrian M, Zarza X, Altabella T, Tiburcio AF, Alcazar R (2012) Polyamines under abiotic stress: metabolic crossroads and hormonal crosstalks in plants. Metabolites. 2:516-528.

Burke JJ, Wanjura DV (2010) Plant responses to temperature extremes. In: Stewart JM, Oosterhuis DM, Heitholt JJ, Mauney JR (Eds), Physiology of Cotton. Springer, Dordrecht, the Netherlands, pp. 123-128.

Constable GA, Oosterhuis DM (2010) In: Stewart JM, Oosterhuis DM, Heitholt JJ, Mauney JR (eds) Physiology of cotton, Springer, Dordrecht, Germany.
Couee I, Sulmon C, Gouesbet G, El Amrani A (2006) Involvement of soluble sugars in reactive oxygen species balance and response to oxidative stress in plants. J Exp Bot. 57:449-459.

Cuevas JC, Lopez-Cobollo R, Alcazar R, Zarza X, Koncz C, Altabella T, Salinas J, Tiburcio AF, Ferrando A (2009) Putrescine as a signal to modulate the indispensable ABA increase under cold stress. Plant Signal Behav. 4:219-220.

Dash S, Mohanty N (2002) Response of seedlings to heatstress in cultivars of wheat: Growth temperature dependent differential modulation of Photosystem I and II activity, and foliar antioxidant defense capacity. J Plant Phys. 159:49-59.

Dat JF, Foyer CH, Scott IM (1998) Changes in salicylic acid and antioxidants during induced thermotolerance in mustard seedlings. Plant Phys. 118:1455-1461.

Dinar M, Rudich J (1985) Effects of heat stress on assimilate metabolism in tomato flower buds. Ann Bot. 56:249-257.

Djanaguiraman M, Prasad PVV, Schapaugh WT (2013) High day- or nighttime temperature alters leaf assimilation, reproductive success, and phosphatidic acid of pollen grain in soybean [Glycine $\max$ (L.) Merr. ]. Crop Sci. 53:15941604.

Drolet G, Dumbroff EB, Legge RL, Thompson JE (1986) Radical scavenging properties of polyamines. Phytochemistry. 25:367-371.

Echer FR, Oosterhuis DM, Loka DA, Rosolem CA (2014) High night temperatures during the floral bud stage increase the abscission of reproductive structures in cotton. J Agron Crop Sci. 200:191-198.

Fitter AH, Hay RKM (1987) Environmental physiology of plants. Academic Press, London, UK.

Frottin F, Espagne C, Traverso JA, Mauve C, Valot B, Lelarge-Trouverie C, Zivy M, Noctor G, Meinnel T, Giglione C (2009) Cotranslational proteolysis dominates glutathione homeostasis to support proper growth and development. Plant Cell. 21:3296-3314.

Fu GF, Song J, Li Y, Le MK, Xiong, J, Tao LX (2010) Alterations of panicle antioxidant metabolism, carbohydrate content and pistil water potential involved in spikelet sterility in rice under water stress. Rice Sci. 17:457-567.

Guinn G (1974) Abscission of cotton floral buds and bolls as influenced by factors affecting photosynthesis and respiration. Crop Sci. 14:291-293.

Hedhly A, Hormaza JI, Herrero M (2009) Global warming and sexual plant reproduction. Trends Plant Sci. 14:30-36.

Hendrix DL (1990) Carbohydrates and carbohydrate enzymes in developing cotton ovules. Physiol Plant. 78:85-92.

IPCC (Intergovermental Panel on Climate Change) (2007) Climate change 2007: Impacts, adaptation and vulnerability. In: Contribution of working group II to Fourth Assessment report of the intergovernmental panel on climate change, Parry ML, Canziani OF, Palutikof JP, van der Linden PJ, Hanson CE (eds) 1000, Cambridge University Press, Cambridge, UK.

Kanno K, Mae T, Makino A (2009) High night temperature stimulates photosynthesis, biomass production and growth during vegetative stage of rice plants. Soil Sci Plant Nutr. 55:124-131.

Kaplan F, Kopka J, Haskell DW, Zhao W, Schiller CK, Gatzke N, Sung DY, Guy CL (2004) Exploring the temperature-stress metabolome of Arabidopsis. Plant Phys. 136:4159-4168. 
Kim TE, Kim SK, Han TJ, Lee JS, Chang SC (2002) ABA and polyamines act independently in primary leaves of cold-stressed tomato (Lycopersicon esculentum). Physiol Plant. 115:370-376.

Kumar SV, Sharma ML, Rajam MV (2006) Polyamine biosynthetic pathway as a novel target for potential applications in plant biotechnology. Plysiol Mol Biol Plants. 12:13-28.

Lawrence C, Holaday AS (2000) Effects of mild night chilling on respiration of expanding cotton leaves. Plant Sci. 157:233-244.

Liu JH, Kitashiba H, Wang J, Ban Y, Moriguchi T (2007) Polyamines and their ability to provide environmental stress tolerance to plants. Plant Biotech. 24:117-126.

Liu YH, Offler CE, Ruan YL (2013) Regulation of fruit and seed response to heat and drought by sugars as nutrients and signals. Frontiers Plant Sci. 4:1-12.

Liu H, Liu Y, Yu B, Liu Z, Zhang W (2004) Increased polyamines conjugated to tonoplast vesicles correlate with maintenance of the $\mathrm{H}^{+}$-ATPase and $\mathrm{H}^{+}$-PPase activities and enhanced osmotic stress tolerance in wheat. J Plant Growth Regul. 23:156-165.

Loka DA, Oosterhuis DM (2010) Effect of high night temperatures on cotton respiration, ATP levels and carbohydrate content. Environ Exp Bot. 68:258-263.

Loka DA, Oosterhuis DM (2014) Water-deficit effects on pistil biochemistry and leaf physiology in cotton (Gossypium hirsutum L.). South Afr J Bot. 93:131-136.

Loka DA, Oosterhuis DM, Mattice JD, McMichael BL (2013) Polyamine metabolism of the cotton flower and its subtending leaf under water-deficit stress in the field. Am J Plant Sci. 4:84-91.

McDonald AE, Vanlerberghe GC (2005) Alternative oxidase and plastoquinol terminal oxidase in marine prokaryotes of the Sargasso Sea. Gene. 349:15-24.

Mohammed AR, Tarpley L (2009) Impact of high nighttime temperature on respiration, membrane stability, antioxidant capacity and yield of rice plants. Crop Sci. 49:313-322.

Mohammed AR, Tarpley L (2010) Effects of high night temperature and spikelet position on yield-related parameters of rice (Oryza sativa L.) plants. Europ J Agron. 33:117-123.

Oosterhuis DM, Loka DA (2012) Polyamines and cotton flowering. In: Oosterhuis DM, Cothren JT (eds) Flowering and Fruiting in Cotton, The Cotton Foundation, Cordova, TN, pp.

Oosterhuis DM, Snider JL (2011) High temperature stress on floral development and yield of cotton. In: Oosterhuis DM (ed) Stress physiology in cotton, The Cotton Foundation, Cordova, TN

Peet MM, Bartholomew M (1996) Effect of night temperature on pollen characteristics, growth and fruit set in tomato. J Amer Soc Hort Sci. 121:514-519.

Prasad PVV, Pisipati SR, Ristic Z, Bukovnik U, Fritz AK (2008) Impact of nighttime temperature on physiology and growth of spring wheat. Crop Sci. 48:2372-2380.

Prasad PVV, Djanaguiraman M (2011) High night temperature decreases leaf photosynthesis and pollen function in grain sorghum. Funct Plant Biol. 38:993-1003.

Quinet M, Ndayiragije A, Lefevre I, Lambillotte B, DupontGillain CC, Lutte S (2010) Putrescine differently influences the effect of salt stress on polyamine metabolism and ethylene synthesis in rice cultivars differing in salt resistance. J Exp Bot. 61:2719-2733.
Reddy KR, Hodges HF, McCarty WH, McKinion JM (1996) Weather and cotton growth: present and future. In: Reddy $\mathrm{KH}$ (ed) Ag. Communic. Division of Agric., Forest and Vet. Med. Bulletin, 1061, Mississippi State, MS.

Reddy KR, Hodges HF, McKinion JM (1997) Modeling temperature effects on cotton internode and leaf growth. Crop Sci. 37:503-509.

Reicheld JP, Khafif M, Riondet C, Droux M, Bonnard G, Meyer Y (2007) Inactivation of thioredoxin reductases reveals a complex interplay between thioredoxin and glutathione pathways in Arabidopsis development. Plant Cell. 19:1851-1865.

Roy M, Wu R (2001) Arginine decarboxylase transgene expression and analysis of environmental stress tolerance in transgenic rice. Plant Sci. 160:869-875.

Salvucci ME, Crafts-Brandner SJ (2004) Inhibition of photosynthesis by heat stress. The activation state of rubisco as a limiting factor in photosynthesis. Physiol Plant. 120:179-186.

Schrader SM, Wise RR, Wacholtz WF, Ort DR, Sharkey TD (2004) Thylakoid membrane response to moderately high leaf temperature in Pima cotton. Plant Cell Environ. 27:725-733.

Selote DS, Khanna-Chopra R (2004) Drought-induced spikelet sterility is associated with an inefficient antioxidant defense in rice panicles. Physiol Plant. 121:462-471.

Singh RP, Prasad PVV, Sunita K, Giri SN, Reddy KR (2007) Influence of high temperature and breeding for heat tolerance in cotton: a review. Adv Agron. 93:313-386.

Snider JL, Oosterhuis DM, Skullman BW, Kawakami EM (2009) Heat-stress induced limitations to reproductive success in Gossypium hirsutum. Physiol Plant. 137:125138.

Snider JL, Oosterhuis DM, Loka DA, Kawakami EM (2011) High temperature limits in vivo pollen tube growth rates by altering diurnal carbohydrates balance in field-grown Gossypium hirsutum pistils. J Plant Phys. 168:1168-1175.

Song J, Nada K, Tachibana S (2002) Suppresion of Sadenosylmethionine decarboxylase activity is a major cause for high-temperature inhibition of pollen germination and tube growth in tomato (Lycopersicon esculentum Mill.). Plant Cell Phys. 43:619-627.

Turnbull MH, Murthy R, Griffin KL (2002) The relative impacts of daytime and nighttime warming on photosynthetic capacity in Populus deltoides. Plant Cell Environ. 25:1729-1737.

Verma S, Mishra SN (2005) Putrescine alleviation of growth in salt stressed Brassica juncea by inducing antioxidative defense system. J Plant Phys. 162:669-677.

Warrag MO, Hall AE (1984) Reproductive responses of cowpea [Vigna unguiculata (L.) Walp.] to heat stress: II. Responses to night air temperatures. Field Crops Res. 8:1733.

Willekens H, Chamnongpol S, Davey M (1997) Catalase is a sink for $\mathrm{H}_{2} \mathrm{O}_{2}$ and is indispensable for stress defense in $\mathrm{C}_{3}$ plants. EMBO J. 16:4806-4816.

Yoon ST, Hoogenboom G, Flitcroft I, Bannayan M (2009) Growth and development of cotton (Gossypium hirsutum L.) in response to $\mathrm{CO}_{2}$ enrichment under two different temperature regimes. Environ Exp Bot. 67:178-187. 